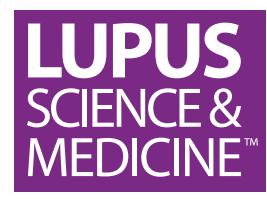

\title{
DNA methylation 101: what is important to know about DNA methylation and its role in SLE risk and disease heterogeneity
}

\author{
Cristina M Lanata, Sharon A Chung, Lindsey A Criswell
}

To cite: Lanata CM, Chung SA, Criswell LA. DNA methylation 101: what is important to know about DNA methylation and its role in SLE risk and disease heterogeneity. Lupus Science \& Medicine 2018;5:e000285. doi:10.1136/ lupus-2018-000285

Received 18 June 2018 Accepted 25 June 2018

\section{Check for updates}

\section{(c) Author(s) (or their} employer(s)) 2018. Re-use permitted under CC BY-NC. No commercial re-use. See rights and permissions. Published by BMJ.

Russell/Engleman Rheumatology Research Center, Department of Medicine, University of California San Francisco, San Francisco, California, USA

Correspondence to Professor Lindsey A Criswell; lindsey.criswell@ucsf.edu

\section{ABSTRACT}

SLE is a complex autoimmune disease that results from the interplay of genetics, epigenetics and environmental exposures. DNA methylation is an epigenetic mechanism that regulates gene expression and tissue differentiation. Among all the epigenetic modifications, DNA methylation perturbations have been the most widely studied in SLE. It mediates processes relevant to SLE, including lymphocyte development, $X$-chromosome inactivation and the suppression of endogenous retroviruses. The establishment of most DNA methylation marks occurs in utero; however, a small percentage of epigenetic marks are dynamic and can change throughout a person's lifetime and in relation to exposures. In this review, we discuss the current understanding of the biology of DNA methylation and its regulators, the measurement and interpretation of methylation marks, the effects of genetics on DNA methylation and the role of environmental exposures with relevance to SLE. We also summarise research findings associated with SLE disease risk and heterogeneity. The robust finding of hypomethylation of interferon-responsive genes in patients with SLE and new associations beyond interferon-responsive genes such as cell-specific methylation abnormalities are described. We also discuss methylation changes associated with lupus nephritis, autoantibody status and disease activity. Lastly, we explore future research directions, emphasising the need for longitudinal studies, cell tissue and contextspecific profiling, as well as integrative approaches. With new technologies, DNA methylation perturbations could be targeted and edited, offering novel therapeutic approaches.

\section{INTRODUCTION}

In the last 20 years, there have been major advances in our understanding of the underlying genetic risk for SLE, with $>80$ established susceptibility loci. ${ }^{1}$ As our knowledge advances, the estimated heritability of SLE has increased from $12 \%$ to $43.9 \% .^{2}$ Nevertheless, genetic factors do not fully explain disease susceptibility, and environmental exposures such as smoking, ultraviolet (UV) light, infections, the microbiome, virome, diet and stressful events have all been associated with disease risk. ${ }^{3}$ Epigenetic modifications may link environmental exposures to changes in gene regulation that lead to disease, and it has been hypothesised as a mechanism contributing to the missing heritability of SLE. Among all the epigenetic modifications, DNA methylation perturbations have been the most widely studied in SLE. ${ }^{4}$ DNA methylation can be transmitted from parent to daughter cells, ${ }^{5}$ indicating that this form of epigenetic modification could represent a molecular mediator capable of propagating the memory of past cellular perturbations. ${ }^{6}$ In this review, we summarise the current understanding of mechanisms of DNA methylation, technical considerations related to its measurement and interpretation, and the current understanding relating it to SLE risk and disease heterogeneity.

\section{Definition of epigenetics}

Epigenetic processes modify gene expression without changing the DNA sequence of the gene. The definition of epigenetics has evolved substantially. In the $1950 \mathrm{~s}$, the concept of epigenetic systems as mediators of cellular memory and cellular identity arose. ${ }^{7}$ In the 1970s, DNA methylation was proposed to be a transcriptional regulatory mechanism that could be maintained through cell division. ${ }^{8}$ By linking DNA methylation to an epigenetic phenomenon, the definition of epigenetics became a molecular one. The development of next-generation sequencing for studying DNA methylation and other regulatory processes genome-wide has resulted in further evolution of the definition of epigenetics to encompass virtually all genome-wide chromatin modifications that do not change the underlying DNA sequence, including DNA methylation, histone modifications, chromatin accessibility, microRNA regulations and two-dimensional chromatin interactions. ${ }^{10}$ Such changes in DNA and chromatin structure correlate with changes in chromatin 


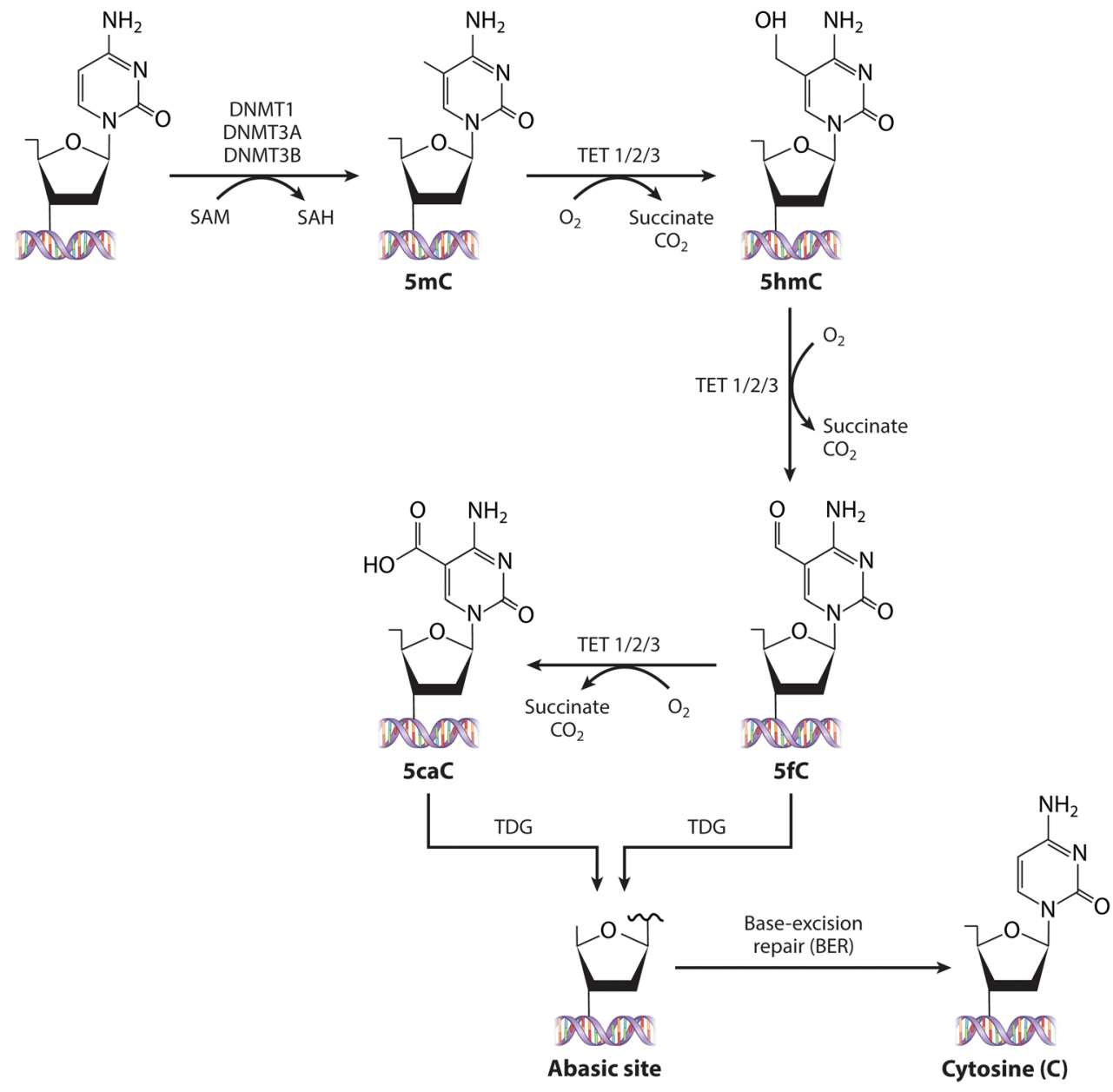

4 Martin EM, Fry RC. 2018

Annu. Rev. Public Health. 39:309-33

Figure 1 DNA methylation and demethylation. Representation of DNA methylation: The addition of a methyl group at the fifth carbon position of the cytosine base. This process is mediated by the DNA methyltransferase (DNMT) enzyme family. DNA demethylation is mediated by the ten eleven translocation (TET) enzyme family. Active demethylation is a sequential process in which 5-methylcytosine is converted to 5 -hydroxymethylcytosine $(5-\mathrm{hmC})$, which is converted to 5 -formylcytosine $(5$-fC) and finally 5 -carboxylcytosine (5-caC). This process readies the sites for thymine-DNA glycosylase (TDG) to remove both 5-fC and 5-caC. BER, base excision repair; OG, oxoglutarate; SAH, S-adenosyl-L-homocysteine; SAM, S-adenosyl-L-methionine. Adapted with permission from Martin et al. ${ }^{105}$

accessibility and transcription factor binding, which can lead to changes in gene expression. Among these, DNA methylation is the best-studied epigenetic modification in SLE.

\section{DNA methylation}

DNA methylation occurs when a methyl group is added to the fifth carbon of cytosine residues that are linked by a phosphate to a guanine nucleotide (a CpG dinucleotide) by DNA methyltransferases (DNMT1, DNMT3A and DNMT3B). This addition forms 5-methylcytosine (figure 1). ${ }^{11}$ The methyl group is obtained from the methyl donor $\mathrm{S}$ adenosine methionine (SAM). SAM levels are influenced by dietary intake of vitamins such as folic acid, vitamin B12 and pyridoxal phosphate (vitamin B6). CpG dinucleotides are methylated in a tissue and cell-type-specific manner, and their methylation critically influences cell differentiation and tissue development. ${ }^{12} 13$
DNA methylation and transcriptional regulation

\section{Key points}

- DNA methylation occurs in $\mathrm{CpG}$ nucleotides that are distributed unevenly across the genome.

- DNA methylation patterns are cell and tissue specific.

- Methylation of CpGs in the promoter region is associated with gene repression.

- Hypomethylation in the promoter region and hypermethylation in the gene body are associated with gene expression.

- Methyl-binding proteins localise to methylated DNA to form inactive and compact heterochromatin.

DNA methylation effects on transcriptional regulation differ depending on the location of the CpG site (intragenic vs promoter region vs enhancer). Most of the genome does not contain CpG sites. However, 


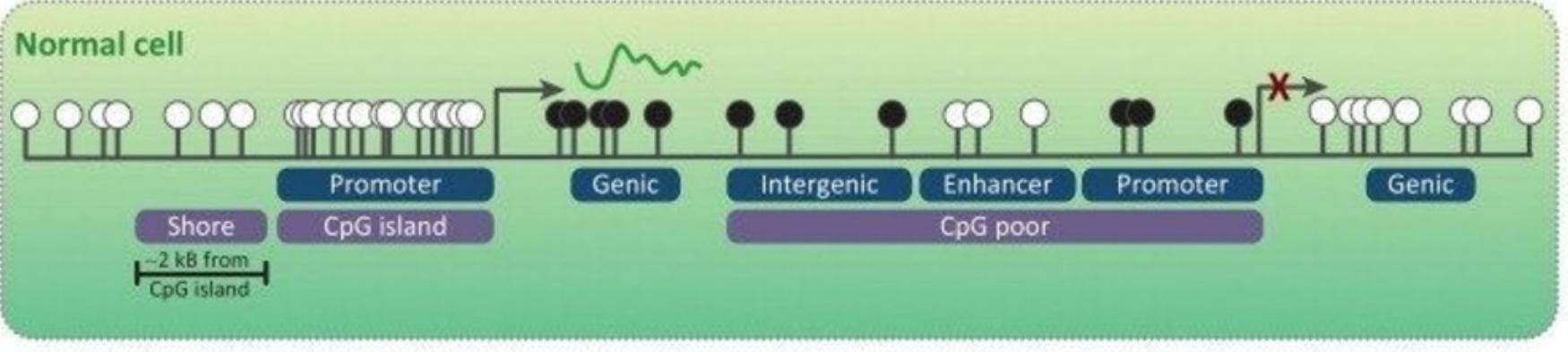

Figure 2 A schematic representation of the genome. White $\mathrm{CpG}$ sites reflect non-methylated $\mathrm{CpG}$ sites. Black represents methylated $\mathrm{CpG}$ sites. Gene expression can occur in the setting of unmethylated $\mathrm{CpG}$ sites in the promoter region and methylated $\mathrm{CpG}$ sites at the gene body (genic). Adapted with permission from Stirzaker et al. ${ }^{14}$

clusters of CpG sites, termed 'CpG islands', occur and commonly span promoters of house-keeping genes. These promoter CpG islands typically remain unmethylated, resulting in active gene expression (CpG island, promoter; figure 2) ${ }^{14}$ Methylated $\mathrm{CpG}$ island promoters are associated with gene repression. CpG island 'shores' are regions of comparatively low $\mathrm{CpG}$ density, located approximately $2 \mathrm{~kb}$ from $\mathrm{CpG}$ islands. Shores also exhibit tissue-specific differential methylation and methylation of shores is associated with gene silencing. Gene bodies tend to have intermediate CpG densities. Unlike CpG island promoters, extensive exonic or genic methylation is typically associated with active gene expression. Beyond these regions, the genome has a lower-than-expected frequency of CpG sites which are typically methylated (intergenic; figure 2). This includes CpG-poor promoters and distal enhancers that regulate tissue-specific genes. ${ }^{15}$ DNA methylation frequently occurs in repeated genetic sequences and helps to suppress the expression and mobility of transposable elements and retroviral elements such as long interspersed nuclear element 1 (LINE-1). ${ }^{16}$

Demethylated promoter regions of genes are thought to facilitate gene transcription by allowing a mechanical opening and accessibility of DNA to transcription factor binding and therefore gene expression. However, recent studies have shown that transcription factor binding can induce DNA hypomethylation in some situations, therefore making it difficult to establish a generalised rule about the relationship between DNA methylation and gene transcription. ${ }^{17}$ DNA methylation is also associated with other epigenetic mechanisms such as histone modifications, particularly the absence of histone H3 lysine 4 methylation (H3K4me0) and the presence of $\mathrm{H} 3$ lysine 9 demethylation (H3K9me2). These histone marks are associated with gene silencing.

DNA methylation can also influence transcription of genes through methyl binding domain proteins (MBDs) ${ }^{18}$ MBDs recruit histone-modifying and chromatin-remodelling complexes to methylated sites, thereby forming compact, inactive heterochromatin.
MBD2 has been linked to immune system function and studied in the context of autoimmunity. Although loss of MBD2 results in reduced numbers of T regulatory (Treg) cells, MBD2 null mice surprisingly do not develop autoimmunity. In humans, increased levels of MBD2 and global demethylation in $\mathrm{CD} 4+\mathrm{T}$ cells have been observed in several autoimmune disorders, including SLE. ${ }^{19}{ }^{20}$ However, considerable effort will be required to fully understand the complexities of MBD2 function in autoimmunity.

\section{Establishing and maintaining DNA methylation marks}

\section{Key points}

DNA methylation occurs during gametogenesis and after fertilisation.

- After each cell division, methylation marks are maintained by the DNA methyltransferases DNMT1, DNMT3A and DNMT3B.

- The majority of methylation marks are stable; however, between $10 \%$ and $20 \%$ on average vary over time.

- It is unclear how methylation marks vary over time in patients with SLE.

DNA is methylated by DNA methyltransferases DNMT1, DNMT3A and DNMT3B. ${ }^{21} 22$ They are highly expressed in undifferentiated cells and germ cell precursors, but present at much lower levels in somatic cells. During each cell replication, fully methylated CpG sites are converted into hemimethylated sites, which are then re-methylated primarily by methyltransferase DNMT1. ${ }^{23}$ These methylation marks are preserved for the rest of the life of an organism, with small tissue-specific changes. ${ }^{23}$ Of note, recent studies suggest that rearrangement of DNMT protein domains influences their enzymatic activity, which may contribute to the development of disease (both autoimmune and non-autoimmune) ${ }^{24-27}$

Methylation patterns of the germline and somatic cell lineages are established during early embryonic development. Methylation of $\mathrm{CpG}$ sites can also persist from the germline of one parent to the zygote, marking the region as being inherited from one parent or the other, 
known as genetic imprinting. ${ }^{28}$ Increasing evidence from animal models and human observational studies suggests that the 'programming' for various adverse health outcomes occurs during the in utero and early postnatal period, likely by disturbing DNA methylation marks. For example, maternal exposure to environmental polybrominated diphenyl ethers has been associated with decreased methylation of the tumour necrosis factor alpha (TNF $\alpha)$ promoter and increased $\mathrm{TNF} \alpha$ protein levels in umbilical cord blood obtained at infant delivery. ${ }^{29}$ Although multiple studies have associated DNA methylation aberrations with in utero environmental exposures (table 1), their role in SLE remains unknown.

\section{How stable are DNA methylation marks?}

Studies of the temporal stability of DNA methylation in healthy individuals indicate that the majority of $\mathrm{CpG}$ sites are stable over time, with only $8 \%-18 \%$ of CpGs varying in methylation status over $6-10$ years. ${ }^{30-32}$ A study comparing monozygotic twins of different ages ( 3 and 50 years) revealed that epigenetic differences between twins increase throughout life, presumably as a consequence of different environmental exposures. A recent twin study indicated that among CpGs exhibiting variation, variation of $90 \%$ of the sites was explained solely by the individual's unique environmental factors and only $10 \%$ of these sites were influenced by familial factors (genetic or shared environment). ${ }^{33}$ A recent study examined the stability of methylation marks in the promoter region of two genes previously associated with SLE, CD $3 Z$ and VHL, in 16 patients at two points in time (median 24 months between assessments). This study found that methylation of the $C D 3 Z$ promoter between the two time points from each patient was modestly correlated $(r=0.488)$. In contrast, DNA methylation levels were highly correlated for CpGs at the VHL promoter ( $\mathrm{r}=0.942$ ), suggesting that some methylation marks change over time while others do not. ${ }^{34}$ Further longitudinal studies of DNA methylation marks in SLE are needed to assess their relationship to disease activity and treatment response.

\section{Important functions of DNA methylation relevant to SLE Lymphocyte development}

During their development, lymphocytes undergo a series of cell-fate decisions that are mediated by changing patterns of DNA methylation. Many genes that are initially methylated in haematopoietic stem cells undergo selective demethylation in a tissue-specific or lineage-specific manner. DNMT1 is required for proper maturation of thymic progenitors, ${ }^{35}$ and conditional deletion of DNMT1 in early double-negative $\left(\mathrm{CD}^{-}, \mathrm{CD} 8^{-}\right)$thymocytes is followed by cellular and DNA replication and DNA demethylation. This is relevant since naïve $\mathrm{T}$ cells from patients with SLE have been reported to have global hypomethylation due to decreased DNMT1 activity. In addition, DNA methylation influences the expression of $\mathrm{T}$ cell cytokines interleukin (IL)-2, IFN-gamma, IL-4 and
IL-13, ${ }^{35} 36$ and the Treg-canonical transcription factor, FOXP3. ${ }^{37}$

\section{$X$ chromosome inactivation}

$\mathrm{X}$ chromosome inactivation (XCI) in female embryos, which occurs early in zygote development, is also mediated by DNA methylation. In females, one X chromosome is randomly selected for chromosome-wide transcriptional silencing, which equalises the expression of $\mathrm{X}$-linked genes between genders. ${ }^{38}$ During development and ageing, varying degrees of escape from XCI via demethylation can occur in cells within a tissue resulting in phenotypic differences. ${ }^{39}$ The female bias observed in SLE has been associated with genes that escape XCI. The X chromosome has the greatest density of immunity-related genes outside of the major histocompatibility complex (MHC) region, and overexpression of these genes is a critical factor in the breakdown of self-tolerance. Individuals with Turner syndrome (XO) have a low risk of developing SLE compared with XX females. ${ }^{40}$ Individuals with Klinefelter's syndrome (XXY) have a 14-fold increased risk of developing SLE compared with $\mathrm{XY}$ males, ${ }^{41}$ suggesting that gene dosage from the $\mathrm{X}$ chromosome influences SLE susceptibility. Consistently, CD4+ T and B cells from women with SLE are found to have demethylated promoters and subsequent overexpression of the X-linked genes CD4OLG, TLR7, CXCR3 OGT, miR-98, let-7f-2, miR 188-3 p, miR-421 and miR-503, suggesting that their overexpression results from a reactivated X chromosome. ${ }^{3842} 43$

\section{Suppression of endogenous retroviruses and other transposable} elements

The high interferon (IFN) signature seen in SLE may be due to over-transcription of retrotransposable elements, resulting from DNA methylation aberrations. Retrotransposable elements or endogenous retroviruses (ERVs) comprise as much as $40 \%$ of the human genome. Some retrotransposable elements have substantial copy number, such as 300000 for Alu elements, and 10000 for LINEs. ${ }^{2}$ Most ERVs in the genome are silenced by DNA methylation. ${ }^{445}$ Sensors of nucleic acids that provide protection from viral infection are implicated in sensing ERVs and can trigger an IFN response. Therefore, the role of ERVs as potential triggers of IFN production in SLE has been examined. A recent study showed that the transcription of LINE-1 is increased in kidney tissue from patients with lupus nephritis and that increased LINE-1 transcription correlates with greater expression of type I IFN. ${ }^{46}$ Furthermore, methylation of CpG sites in the LINE-1 promoter is negatively correlated with LINE-1 expression. Thus, demethylation may play a critical role in the overexpression of LINE-1. ${ }^{46}$ HRES-1, another ERV, has been shown to be overexpressed in SLE. SLE B cells have been characterised by their incapacity to methylate the HRES-1 promoter, both in unstimulated and in anti-IgM stimulated B cells. ${ }^{47}$ 
Table 1 Exposures associated with DNA methylation changes and their associations with SLE as well as other diseases

\begin{tabular}{|c|c|c|c|c|}
\hline Exposure & DNA methylation changes & Disease associations & SLE associations & Ref \\
\hline Arsenic & $\begin{array}{l}\text { Hypomethylation of genes } \\
\text { involved in cell adhesion } \\
\text { and communication; LINE-1 } \\
\text { hypomethylation; hypomethylation } \\
\text { in genes } \\
\text { KCNQ1, SQSTM, MMP-9, TIMP-1, } \\
\text { FYN, BST1, XYLT1, PTPRN2 and } \\
\text { PARD3 }\end{array}$ & $\begin{array}{l}\text { Cancer, lung conditions, } \\
\text { diabetes, CVD. } \\
\text { Prenatal exposure was } \\
\text { associated with increased } \\
\text { incidence of infection, } \\
\text { neurocognitive effects } \\
\text { and increased neonatal } \\
\text { mortality }\end{array}$ & $\begin{array}{l}\text { Arsenic exposed population } \\
\text { had increase in positive ANA, } \\
\text { serum levels of IL6 and IL8 }\end{array}$ & $110-114$ \\
\hline Air pollution & $\begin{array}{l}\text { Global hypomethylation; LINE-1 } \\
\text { hypomethylation; } \\
\text { Specific genes: MAPK pathway } \\
\text { members, ACE, iNOS, ICAM-1, }\end{array}$ & $\begin{array}{l}\text { Accelerated lung ageing, } \\
\text { loss of lung capacity, } \\
\text { asthma, bronchitis, } \\
\text { emphysema and cancer }\end{array}$ & $\begin{array}{l}\text { Increase in SLEDAI score, } \\
\text { increase in risk of SLE and } \\
\text { other rheumatic diseases }\end{array}$ & $115-120$ \\
\hline
\end{tabular}

\begin{tabular}{|c|c|}
\hline Bisphenol A & $\begin{array}{l}\text { Hypomethylation of } \mathrm{CpG} \\
\text { targets on the } \mathrm{X} \text { chromosome; } \\
\text { hypomethylation in genes } \\
\text { associated with immune function, } \\
\text { transport activity and metabolism; } \\
\text { hypomethylation of SNORD, } \\
\text { SULT2A1, COMT; reduced } \\
\text { expression of DNMT1 }\end{array}$ \\
\hline Cadmium & $\begin{array}{l}\text { MGMT, MT2A, DNMT3B and LINE- } \\
1 \text { hypomethylation in a sex-specific } \\
\text { manner; } \\
\text { DNMT1 hypomethylation }\end{array}$ \\
\hline
\end{tabular}

Neurocognitive effects,
increased incidence
of cancer and heart
conditions from prenatal
exposure

Autoantibody production in a $121-126$ murine model for SLE; BPAinduced signalling in murine and human myeloid cells stimulates the type I IFNsignalling Cancer, lung, bone
and kidney disease,
developmental toxicity

Autoimmunity in animal $127-132$ models, including increased expression of ANA, immune complex deposition in the kidneys and antibody production in susceptible mouse models

\begin{tabular}{|c|c|c|c|c|}
\hline Mercury & $\begin{array}{l}\text { Hypomethylation in genes EMID2, } \\
\text { PON1 }\end{array}$ & Neurotoxicity & $\begin{array}{l}\text { Higher risk of SLE in dental } \\
\text { workers exposed to mercury }\end{array}$ & $127133-138$ \\
\hline $\begin{array}{l}\text { Persistent } \\
\text { organic } \\
\text { pollutants }\end{array}$ & $\begin{array}{l}\text { Hypomethylation of LINE-1 and Alu } \\
\text { elements; } \\
\text { Hypomethylation of genes IGF2, } \\
T N F-\alpha \text {, and NR3C1 }\end{array}$ & Various health effects & $\begin{array}{l}\text { ANA positivity; increased risk } \\
\text { of SLE mortality }\end{array}$ & 29 139-142 \\
\hline Pesticides & $\begin{array}{l}\text { Global hypomethylation; } \\
\text { Hypomethylation in genes GPR33, } \\
\text { KCNE2, ANXA1, GSTp1, MGMT; } \\
\text { LINE-1 hypomethylation }\end{array}$ & $\begin{array}{l}\text { Cancer, neurotoxicity, birth } \\
\text { defects, impaired fertility }\end{array}$ & $\begin{array}{l}\text { Higher risk of SLE in exposed } \\
\text { individuals }\end{array}$ & $3143-152$ \\
\hline $\begin{array}{l}\text { Polycyclic } \\
\text { aromatic } \\
\text { hydrocarbons }\end{array}$ & $\begin{array}{l}\text { Global hypomethylation; } \\
\text { hypermethylation of genes HIN1, } \\
\text { ESR1, TWIST1, RAR } \beta, A P C\end{array}$ & Cancer & $\begin{array}{l}\text { Higher risk of SLE in exposed } \\
\text { individuals }\end{array}$ & $\begin{array}{l}101145 \\
153-155\end{array}$ \\
\hline Phthalates & $\begin{array}{l}\text { DMRs in genes related to growth } \\
\text { and development, cellular function } \\
\text { and maintenance; Hypomethylation } \\
\text { of genes ERalpha, IRAK4, ESM1, } \\
\text { BRCA1, LASP1, CNPY1, IFT140, } \\
\text { TESC, PRDM8 }\end{array}$ & Infertility, cancer & $\begin{array}{l}\text { dsDNA production } \\
\text { in lupus-prone mice, } \\
\text { glomerulonephritis in lupus } \\
\text { prone mice }\end{array}$ & $156-162$ \\
\hline Tobacco smoke & $\begin{array}{l}\text { Global hypomethylation; } \\
\text { Hypomethylation of genes } A H R R, \\
\text { CNTNAP2, MYO1G }\end{array}$ & $\begin{array}{l}\text { Cancer, developmental } \\
\text { toxicity, cardiovascular } \\
\text { disease, chronic } \\
\text { respiratory conditions }\end{array}$ & $\begin{array}{l}\text { Higher risk of SLE in exposed } \\
\text { individuals, increased dsDNA } \\
\text { production and cancer in } \\
\text { patients with SLE }\end{array}$ & $106163-170$ \\
\hline Salt & $\begin{array}{l}\text { TET2-induced global DNA } \\
\text { demethylation of Tfh cells }\end{array}$ & & $\begin{array}{l}\text { A high-salt diet markedly } \\
\text { increased lupus features in } \\
\text { MRL/lpr mice }\end{array}$ & 171 \\
\hline
\end{tabular}


Table 1 Continued

\begin{tabular}{llll}
\hline Exposure & DNA methylation changes & Disease associations & SLE associations \\
\hline Stress & Global hypomethylation; & Infant stress reactivity, & Increased risk of SLE in \\
& Hypomethylation of genes NR3C1, & resilience, depression, & exposed individuals, higher \\
& OXTR, CORIN, CFTR, SMYD3, & increased cardiovascular & $\begin{array}{l}\text { rate of SLE flares, early onset } \\
\text { of disease }\end{array}$ \\
& BARX1, CRF, SLC6A4 & disease, cancer & it7
\end{tabular}

CVD,cardiovascular disease; DMR, differentially methylated region; IFN, interferon; IL, interleukin; LINE-1, long interspersed nuclear element 1; SLEDAI, Systemic Lupus Erythematosus Disease Activity Index.

\section{How does aberrant DNA methylation occur?}

\section{Key points}

Methylation changes can occur due to the loss of maintenance of methylation marks by the DNMT enzymes during cell division (passive demethylation) or by active removal of methylation marks by the TET enzymes (active demethylation).

- DNMT dysfunction has been linked to oxidative stress and environmental exposures.

- The role of active demethylation by the TET enzymes in SLE remains to be defined.

- Research regarding the regulators of DNMTs and TET enzymes will likely shed light into disease pathogenesis as well as therapeutic interventions.

\section{Passive DNA demethylation: role of DNMTs and oxidative stress}

Transcription factors, microRNAs and other proteins may influence DNMT activity and could cause DNA methylation aberrations. In SLE, changes in DNMT1 expression have been linked to aberrations in DNA methylation. Significantly lower DNMT1 and DNMT3A transcript levels in patients with SLE were observed compared with healthy controls. ${ }^{48}$ With lower levels of DNMT1, DNA methylation patterns are not completely copied from parent to daughter cells during mitosis, resulting in passive DNA demethylation. DNMT1 is regulated by the mitogen-activated protein kinase/ERK (MAPK/ERK) signalling pathway. Impairment of this pathway causes a failure to upregulate DNMT1 during mitosis and has been shown in vitro and in vivo to contribute to SLE flares. ${ }^{49}$ In SLE, T and $B$ cells with a defective ERK signalling pathway have demethylation and overexpression of methylation-sensitive genes. ${ }^{47}{ }^{50}$ Many studies have linked human SLE flares with heightened oxidative stress. ${ }^{50} 51$ Increased oxidative stress has been implicated in the deregulation of the ERK signalling pathway, leading to DNMT1 downregulation and global DNA demethylation in T cells from patients with SLE ${ }^{50}$ Environmental exposures such as UV light, cigarette smoke, silica and other stressors stimulate reactive oxygen species production, which in turn could lead to DNA methylation aberrations by disrupting the MAPK/ERK pathway. ${ }^{52}$

\section{Active DNA demethylation: the role of 5-TET proteins}

Methylated cytosine can be converted back to unmethylated cytosine by ten eleven translocation (TET) proteins. Unmethylated cytosines are then restored back to the genome through base excision repair. ${ }^{53-57}$ This has been defined as active modification-active removal and is independent of DNA replication (figure 1). The regulation of TET proteins is just beginning to be studied, but factors such as hypoxia, iron, vitamin $\mathrm{C}$ and post-transcriptional and post-translational modifications by microRNAs have been implicated ${ }^{58}$ Generally, studies have shown that key tissue-specific transcription factors recruit TET proteins to sites where CpGs need to be demethylated. Its role has been primarily studied in preimplantation development. This mechanism of demethylation is of interest in processes such as SLE.

\section{How does one assess DNA methylation aberrations?}

\section{Key points}

- Whole genome bisulfite sequencing can profile the $\sim 28$ million $\mathrm{CpG}$ sites inthe human genome, but it is costly and computationally burdensome.

- Arrays are a cost-effective way to asses for genome-wide methylation marks; however they only cover $\sim 4 \%$ of all $\mathrm{CpG}$ sites across the genome.

The current 'gold standard' technique for identifying methylated cytosines across the genome is whole-genome bisulfite sequencing (WGBS). ${ }^{14}$ In this process, DNA is treated with sodium bisulfite, which converts unmethylated cytosine to uracil, leaving methylated cytosines unchanged. Treated DNA then undergoes whole-genome sequencing. WGBS can provide a complete map of the $\sim 28$ million CpG sites in the human genome. ${ }^{59}$ However, the high cost of this approach and significant technical expertise required to generate and process WGBS data precludes application of this method in large cohort studies at this time, and thus no WGBS studies have been performed in SLE.

In recent years, the Illumina HumanMethylation 450 (HM450) BeadChip has provided a user-friendly platform to profile DNA methylation in human samples. The HM450 uses bisulfite-converted genomic DNA hybridised to arrays containing predesigned probes to distinguish methylated (cytosine) and unmethylated (uracil) CpG sites. A single-base step incorporates a labelled nucleotide that is fluorescently stained. Scanning of the array detects the ratio of fluorescent signal arising from the unmethylated probe to the methylated 
probe. The proportion of DNA methylation at a particular CpG site (the methylation beta-value $(\beta)$ ) is calculated by taking the ratio of the methylated to the total (unmethylated+unmethylated) signal. A $\beta$-value of 0 represents a completely unmethylated CpG site, and a $\beta$-value approaching 1 represents a fully methylated CpG site. ${ }^{60}$ Probes have been preferentially designed to target CpG islands due to the established relationship between DNA methylation at promoter CpG islands and gene expression. The HM450 BeadChip interrogates 482422 cytosines, which represents approximately $1.7 \%$ of all CpG sites in the human genome. However, these sites are enriched for $\mathrm{CpG}$ $(99.3 \%)$ islands and almost half of the probes on the array cover intergenic regions, such as bioinformatically predicted enhancers, DNase I hypersensitive sites and validated differentially methylated regions (DMRs). ${ }^{60} 61$ However, the HM450 platform may miss important regulatory regions. Thus, Illumina released the MethylationEPIC (EPIC) BeadChip, with new content specifically designed to target these regions. EPIC covers $>850000 \mathrm{CpG}$ sites, including $>90 \%$ of the CpGs from the HM450 and an additional 413743 CpGs. Even though the additional probes improve the coverage of regulatory elements, only $7 \%$ of distal and $27 \%$ of proximal ENCODE regulatory elements are represented. ${ }^{60}$ An important caveat to remember is that array design is heavily biased due to inclusion of probes that interrogate only CpG sites that have been previously identified in methylation-based assays. Thus, there is a probe selection bias.

\section{Epigenome-wide association studies (EWAS): caveats and pitfalls}

Taking advantage of these new assays to interrogate DNA methylation marks across the genome, studies have been performed comparing individuals with SLE to healthy individuals. These EWAS are modelled after genome-wide association studies and test whether the level of DNA methylation at individual cytosines in the genome differs among individuals with SLE compared with healthy controls. It is inferred that differential methylation of CpG sites likely influences the expression of nearby genes, and thus differential methylation identifies specific genes that may affect SLE risk or the development of specific disease manifestations. This traditional EWAS approach has been criticised by several investigators ${ }^{62-66}$ based in part on complexities related to appropriate quality control, normalisation procedures and adjustments for background noise. These issues have been discussed in depth in several reviews. ${ }^{636667}$ Below we discuss the issue of the interpretability of DNA methylation changes.

\section{What is the hypothesis being tested in EWAS of SLE?}

Most studies examine the association between level of DNA methylation and the outcome of interest. The primary hypothesis is generally that the change in methylation influences changes in gene expression that leads to disease or the change in methylation reflects an exposure associated with disease. However, given the cross-sectional nature of these studies, causality for these associations cannot be determined. The changes in methylation may be a manifestation of the disease itself. While these changes may reflect important pathogenic mechanisms, the inference of causality assumed in these hypotheses may not be valid.

\section{Confounders are not fully accounted for in most SLE EWAS}

\section{Key points}

When performing an epigenome-wide association study, there are important confounders to be considered:

- Differences in cell proportions: When profiling unsorted peripheral blood, DNA methylation marks may reflect changes in cell proportions in cases and controls, rather than disease-associated changes.

- Genetic ancestry as well as genetic variation influence methylation marks.

Medications can alter DNA methylation patterns.

\section{Cell proportions in blood samples}

A well-recognised source of variability of DNA methylation is the difference in cell-subtype proportions between experimental groups. Even when cells are isolated according to their surface markers, single-cell transcriptomics has revealed significant heterogeneity between cells that share the same surface markers. ${ }^{68} 69$ Even though bioinformatic methods exist to adjust for these differences, these methods likely are not able to account for all the methylation differences attributable to cell proportion differences seen between groups. ${ }^{70-72}$ Most EWAS report modest changes in methylation (eg, $20 \%$ change), after correcting for cell-subtype variation. This can be explained if the cellular reprograming is only happening in a subpopulation of cells or if the effects of cell subtypes have not been fully accounted for.

\section{Genetic variation}

Most associated single-nucleotide polymorphisms identified in genome-wide association studies of SLE are in non-coding regions, and thefunctional effects for many are unknown. DNA sequence variations can alter DNA methylation states and gene expression, linking the regulatory genome with individual genetic risk loci. In a recent study examining three major human immune cell types (CD14+ monocytes, CD16+ neutrophils and naive CD4+ T cells) in 197 healthy individuals, genetic variation explained the majority of DNA methylation variance for most genes, leaving a relatively modest independent proportion of DNA methylation changes that can be attributed to environmental effects. ${ }^{73}$

Variation in methylation can be attributed to genetic and non-genetic effects. Non-genetic effects can be 
further categorised as familial (shared environment) and non-familial (unique environment) effects. Studies of SLE discordant twins can also provide evidence of the genetic effect on DNA methylation, assuming the discordant twins share the same environment. Several twin studies have reported the heritability of DNA methylation between $18 \%$ and $37 \% .{ }^{74-76}$ Discordant twin studies of SLE have identified several hypomethylated epigenetic marks associated with SLE in genes such as ITGAL (CD11a), PRF1 (perforin), CD70, GADD45A and IFN-responsive genes, strongly implicating an aetiological role for epigenetic factors in SLE. ${ }^{117}$ Overall, these studies highlight the importance of adequately accounting for effects of genetic variation for proper interpretation of EWAS results. To date, this has only been performed in one SLE EWAS described below.

\section{Effects of population genetics}

Emerging EWAS in various fields has revealed thousands of CpG methylation sites correlated with genetic ancestry. ${ }^{73} 75$ In SLE, a recent study comparing African-American (AA) to European American patients identified ethnic-specific clustering of DNA methylation patterns in naive CD4+ T cells. Pro-apoptotic and pro-inflammatory genes were significantly enriched with hypomethylated CpG sites in healthy AAs, with genetic variants within and directly disrupting CpG sites accounting for some ethnic-specific variability in DNA methylation. ${ }^{78}$ These ethnic-specific differences in methylation may help explain racial disparities in outcomes and disease manifestations observed in SLE. Further work is warranted in this area.

\section{Medication effects}

Medications can alter DNA methylation and are not accounted for in the majority of studies. ${ }^{79}$ In one SLE EWAS, the investigators tested whether methylation levels were associated with the most commonly prescribed medications in SLE. ${ }^{80}$ They found that 5196 differentially methylated CpGs (primarily hypomethylated) were associated with glucocorticoid use and 125 differentially methylated CpGs were associated with azathioprine $\left(p<1.3 \times 10^{-7},|\beta|>0.05\right)$. Methylation changes were not associated with antimalarials, mycophenolate mofetil or methotrexate use. The negative findings associated with methotrexate and mycophenolate are likely a reflection of the small number of patients on these medications $(n=22$ and $n=36$, respectively). Methotrexate use has been shown to reverse methylation changes observed in $\mathrm{B}$ and $\mathrm{T}$ cells of patients with rheumatoid arthritis. ${ }^{81}$ Cyclophosphamide and biologics were not studied. Overall, there are sparse data on the effects of medications on methylation and more studies are needed to confirm these findings.
What have we learned about how changes in DNA methylation affect SLE risk and disease heterogeneity?

Two types of studies have been performed that address this issue: in vitro studies using targeted methylation-based assays and genome-wide studies using microarray data (eg, HM450).

\section{Initial studies}

The relationship between SLE and abnormal DNA methylation status was first described $>20$ years ago, when $\mathrm{T}$ cells from active patients with SLE were observed to have decreased global DNA methylation levels $\left(15 \%-20 \%\right.$ reduction) ${ }^{82}$ In vitro studies revealed that inhibitors of DNMT1 (5-azacytidine, procainamide or hydralazine) could induce hypomethylation with subsequent autoreactivity in naive $\mathrm{T}$ cells, ${ }^{83}$ providing strong evidence for causation in SLE. This was further supported by studies showing that disease activity in patients with SLE inversely correlated with global DNA methylation. ${ }^{84}$ In subsequent experiments, antigen-specific CD4+ T cells epigenetically modified with DNA methylation inhibitors overexpressed genes normally suppressed by this mechanism, including CD11a, CD70, CD 4OL, PRF1 and the KIR gene family. The altered cells became autoreactive, responding to self-class II MHC molecules without added antigen. These cells were sufficient to cause lupus-like disease in syngeneic mice. T cells overexpressing the same genes were found in patients with active SLE. ${ }^{45}$ These $\mathrm{T}$ cells have been further characterised as a specific subset with the following markers: $\mathrm{CD} 3^{+} \mathrm{CD} 4^{+} \mathrm{CD} 28^{+} \mathrm{CD} 11 \mathrm{a}-$ ${ }^{\text {hi }} \mathrm{CD} 70^{+} \mathrm{CD} 40 \mathrm{~L}^{\text {hi }} \mathrm{KIR}^{+}$. The proportion of these cells correlated with the severity of SLE flares. ${ }^{86}$

\section{EWAS in SLE}

\section{Key points}

- The most robust finding from EWAS is the hypomethylation of interferon-responsive genes in patients with SLE compared to healthy controls; this has been observed in unsorted peripheral blood as well as lymphoid and myeloid cells.

- In a twin study of discordant SLE twins, B cells had more robust methylation differences than other cell types, with hypermethylation of CpGs in TRAF5, CXCR5 and DDR1 as novel findings.

- With larger sample sizes, new differentially methylated CpGs are being described beyond interferon-responsive genes.

- These CpGs lie in enhancer and regulatory regions of the genome and implicate genes that are relevant to immune function, such as PDCD1 and TLR8.

- EWAS with larger sample sizes and in diverse populations will likely continue to shed light into the role of DNA methylation in SLE.

\section{Demethylation of IFN-responsive genes}

One of the first EWAS in SLE compared methylation marks in naive $\mathrm{CD} 4+\mathrm{T}$ cells between 36 patients with SLE and 36 controls, using the HM450 array. The investigators identified 86 CpGs that were differentially 
methylated, with $<20 \%$ difference in methylation between patients and controls. Multiple IFN-regulated genes were hypomethylated in naive T cells in patients with SLE, without a corresponding increase in gene expression. The authors introduced the concept of naive $\mathrm{T}$ cells being 'epigenetically poised' to respond to type I IFN upon T cell activation. This builds on the concept that unmethylated CpGs reflect a permissive but not prescriptive transcription state, and gene activation requires additional epigenetic modifiers or transcription factors. Although this study has limitations including failure to control for potential confounders, the findings have been replicated by subsequent SLE EWAS described below. ${ }^{87}$

A second study examined CD19+, CD4+ and CD14+ cells in 49 patients with SLE and 58 controls using the HM450 array and applied more rigorous methods for quality control, including adjustment for ethnicity, age and gender. ${ }^{88}$ Several loci were differentially methylated with significance levels reaching the genome-wide threshold of $p$ value $<1 \mathrm{E}-08$. Methylation differences as large as $40 \%$ were identified in adjusted analyses. Fifty genes were significantly differentially methylated in both $\mathrm{T}$ and $\mathrm{B}$ cells, and differential methylation of 19 genes was highly significant across all three cell types. Although there was significant overlap of demethylated genes across cell types, the authors could detect numerous cell-specific DNA methylation changes. Pathway analyses of the top 100 differentially methylated CpG sites for each cell type identified IFN signalling as the top pathway for CD4+, CD 19+ and CD14+cells. They also observed that the SLE-associated methylation changes in $\mathrm{T}$ cells were heterogeneous, concluding that these effects are likely mediated by different proportions of subpopulations of $\mathrm{CD} 4+\mathrm{T}$ cells. To examine these possibilities, they sorted CD4+ $\mathrm{T}$ cells from an independent cohort of 26 patients with SLE and 18 controls into naive, memory and regulatory $\mathrm{T}$ cells. Only the IFN-related genes remained hypomethylated in all $\mathrm{T}$ cell subtypes, with other $\mathrm{CpG}$ sites restricted to specific subpopulations of $\mathrm{T}$ cells. This same phenomenon was also observed in neutrophils and low-density granulocytes in a study of 15 patients with SLE and 15 healthy matched controls. ${ }^{89}$

The most recently reported EWAS applied the HM450 array to peripheral blood samples from 548 Swedish patients with SLE and 587 matched healthy controls. With a discovery and replication study design, the largest methylation differences $(>10 \%)$ were observed almost exclusively at IFN-regulated genes, with the effect being more prominent in active SLE. ${ }^{80}$ Only one EWAS in patients with SLE of non-European descent has been published, which focused on 12 Chinese patients with SLE and 12 controls. In this study, hypomethylation of MX1, IFI44L, NLRC5 and PLSCR1, all IFN-responsive genes were replicated in patients with SLE.

Although these studies have limitations, the consistent findings of widespread hypomethylation of
IFN-responsive genes in cells from lymphoid and myeloid lineages are compelling. There are at least two potential hypotheses for the observed phenomena. One hypothesis is that these perturbations occurred in an early multipotent progenitor population and were subsequently propagated to lineages that are programmed to respond to IFN. This hypothesis suggests that the in utero environment might be of critical importance since most methylation marks are established during the embryonic period. Another hypothesis is that these studies are capturing the effects of high serum IFN on circulating peripheral immune cells, a hallmark of SLE pathogenesis.

More robust DNA methylation changes in B cells in SLE: the role of hypermethylation and gene silencing

Fifteen SLE twin pairs were recently studied, including six monozygotic, six same-sex dizygotic and three opposite-sex dizygotic twin pairs. Using the HM450 array, four cell types were profiled: CD4+ T cells, B cells, monocytes and granulocytes. Due to the small sample size, the authors focused on gene promoter and transcription start regions and defined a less stringent significance threshold. Among the 13 discordant SLE twin pairs, $35 \%-41 \%$ of all differentially methylated CpGs corresponded to IFN-responsive genes, of which most (but not all) overlapped in four cell types. Differential methylation was more widespread in B cells with predominantly hypermethylation, followed by monocytes, then granulocytes, and finally $\mathrm{CD} 4+\mathrm{T}$ cells. The authors focused on $14 \mathrm{CpG}$ probes of interest for pyrosequencing: 5 IFN-regulated genes, 3 non-IFN genes and 5 genes only differentially methylated in B cells. A CpG site in IFI44L had the largest overall difference observed in discordant SLE twins, with a median hypomethylation of $49.3 \%$ in monocytes and granulocytes. In addition, CpGs from TRAF5, CXCR5 and DDR1 were hypermethylated in B cells from discordant SLE twins. ${ }^{90}$ Of particular interest is TRAF5, which has been recently described as a negative regulator of TLR signalling in B cells. ${ }^{91}$

\section{New findings with larger sample sizes: beyond IFN-responsive genes}

In the latest Swedish SLE EWAS, 4034 differentially methylated sites were novel and annotated to 1638 unique genes that have not previously been associated with SLE. This likely reflects the larger sample size available for that study. Gene ontology enrichment analyses of these sites revealed enrichment in molecular functions related to regulatory function of the genome, such as DNA binding and transcription factor activity. Interestingly, these associated methylation marks were enriched in regions with a histone mark for active enhancers (H3K4me1) in B and T cells. The authors highlighted several CpG sites in genes found to be differentially methylated in lupus such as $P D C D 1$ and $A K 2$. PDCD1 is a confirmed SLE susceptibility locus 
that encodes the programmed cell death 1 protein that prevents autoimmunity by inhibiting activation of self-reactive lymphocytes. AK2 plays a role in apoptotic processes. When examining only females, 27 differentially methylated $\mathrm{CpGs}$ were found on the $\mathrm{X}$ chromosome, including CpGs in genes TLR8 and VSIG4, a negative regulator of T-cell proliferation. In males, three $\mathrm{X}$ chromosome $\mathrm{CpGs}$ in genes SH2D1A and SEPT6 were differentially methylated. This study indicates that there is still much to be learned from DNA methylation profiling not only with larger samples, but from diverse populations.

\section{Genetic control of methylation marks}

GWAS variants associated with risk of SLE have been found to influence methylation levels, suggesting a functional mechanism for these genetic variants. In an integrative analysis of genotype and DNA methylation data, $466 \mathrm{CpG}$ sites of the 7245 differentially methylated sites identified in the Swedish SLE EWAS showed evidence of genetic control. ${ }^{92}$ Six SLE GWAS risk loci and the MHC class III region were associated with differentially methylated $\mathrm{CpG}$ sites: PTPRC (CD45), UHRF1BP1, IRF5, IRF7, IKZF3 and UBE2L3. This suggests that variants at SLE risk loci may in part exert their influence on SLE risk through alteration of DNA methylation levels at regulatory regions of target genes. An example was the UBE2L3 locus: the SLE-associated GWAS SNP is located downstream of the gene, but influences methylation for an SLE-associated CpG of the UBE2L3 promoter region. This study suggests that a small proportion of DNA methylation changes can be attributed to genetic variation.

\section{Methylation changes in relationship to disease activity: transcription factors highlighted}

There are only a few studies examining DNA methylation changes associated with disease activity defined by the SLE Disease Activity Index (SLEDAI) score. A cross-sectional study examining 12 pairs of active patients with SLE and healthy controls found that CpGs in the promoter regions of ILIO and ILIR2 were significantly hypomethylated in the samples of patients with SLE relative to the healthy controls. ${ }^{93}$ Another study of naive CD4+ T cells from 74 patients with SLE examined methylation changes associated with the SLEDAI score using the HM450 array. Using a less stringent threshold of significance, 4839 methylation sites were hypomethylated and 1568 methylation sites were hypermethylated with disease activity in lupus. Transcription factor binding site analysis revealed that hypermethylated sites associated with disease activity were enriched for binding sites of two repressive transcription factors, EZH2 and SUZ12. The authors also showed that reduced methylation in key cytokine genes such as IL4, IL5, IL13, IL12B and ILITF was associated with increased disease activity, suggesting an epigenetic shift towards a Th2 and possibly Th17 response.
Increased SLEDAI scores were associated with hypomethylation of key transcription factors involved in T-cell differentiation such as PU.1, (ROR t) and BCL-6, which promote Th9, Th17 and follicular helper T cell responses, respectively. ${ }^{94}$ One interpretation is that in the setting of an SLE flare the circulating cytokine milieu could induce these subtle methylation changes, which could then programme the naive CD4 $\mathrm{T}$ cell response towards a certain fate once it encounters its cognate antigen. It is unclear whether this would be relevant to the flare itself or perhaps to future flares.

Based on the above finding, recent work explored the role of transcription factor EZH2 in SLE pathogenesis. ${ }^{95}$ EZH2 is an epigenetic regulator that mediates histone H3K27 trimethylation (H3K27me3) and modulates DNA methylation. The authors found that EZH2 was overexpressed in CD4+ T cells in SLE, resulting in hypomethylation of genes involved in leucocyte adhesion and migration, including F11R (which encodes junctional adhesion molecule A [JAM-A]), G11R, SELP and SELPLG. This was further tested in vitro, where overexpression of EZH2 was associated with increased adhesion of activated CD4+ T cells to endothelial cells, mediated by JAM-A. The results of this study identified a novel role of EZH2 in T cell adhesion in SLE, mediated by epigenetic remodelling.

\section{Methylation changes in relationship to disease phenotype}

\section{Key points}

DNA methylation changes have been associated with disease activity, antibody status and lupus nephritis, shedding light on genomic drivers of disease heterogeneity.

- Transcription factors such as EZH2 have been shown to mediate methylation changes leading to increased T-cell adhesion in SLE flares.

- Differentially methylated CpGs in TNK2, DUSP5, MAN1C1, PLEKHA1, IRF7, HIF3A, IFI44 and PRR4 have been associated with lupus nephritis.

- Overall, hypomethylation of interferon-responsive genes is associated with higher disease activity, renal disease, as well as autoantibodies.

- Replication of these findings in larger studies that capture active disease manifestations is needed to further define the role of DNA methylation in disease heterogeneity.

SLE is a complex disease, with disease manifestations that can range from mild to life-threatening. Although significant efforts have been made to understand the genomic causes of SLE risk, there are increasing efforts to better characterise the genomic drivers of disease heterogeneity and outcomes. DNA methylation has been studied in relation to several SLE phenotypes that we discuss below.

\section{Lupus nephritis}

Two EWAS have been published examining lupus nephritis using the HM450 chip. One study looked at naive CD4+ T cells in a multiethnic cohort of 28 SLE patients 
with nephritis, 28 SLE patients without nephritis and 56 healthy controls. Out of the 191 differentially methylated CpG sites unique to lupus patients with renal involvement, 64 were hypomethylated and 127 were hypermethylated compared with healthy matched controls. The two most hypomethylated genes were TNK2 and DUSP5, and the two most hypermethylated genes were MAN1C1 and PLEKHA1, with all CpGs having an overall methylation difference of $20 \%$. IFN-responsive genes were hypomethylated to a greater extent in patients with renal involvement, and the authors highlighted the IFN regulatory factor family member gene $I R F 7$, which was demethylated only in SLE patients with renal disease. TNK2 encodes a non-receptor tyrosine kinase that modulates many downstream effector molecules and is involved in cell trafficking, endocytosis, cell migration and tissue invasion. DUSP5 encodes a phosphatase that can dephosphorylate MAPK/ERK, a pathway implicated in the pathogenesis of SLE. ${ }^{96}$

The second study analysed 322 women of European descent with SLE, of whom 80 had a history of lupus nephritis (LN). The investigators analysed peripheral blood mononuclear cells and applied methods to adjust for population substructure and leucocyte cell proportions. The investigators identified differential methylation of 19 sites in 18 genomic regions that were associated with nephritis among patients with SLE (false discovery rate $\mathrm{q}<0.05$ ), with the largest differences approaching $10 \%$. Associations with hypomethylation in four sites in HIF3A, IFI44 and PRR4 were replicated when examining methylation data derived from CD4+ T cells collected from the EWAS described above. The authors highlighted HIF3A. Its gene product, HIF, can activate the transcription of $>100$ genes involved in the cell's response to hypoxia. Chronic hypoxia in the tubulointerstitium of the kidney has been proposed as a common pathway that leads to end-stage renal disease, and thus HIF plays a critical pathophysiological role in this process. Of the other CpG sites, only four (IFI44, IFIT1, DDX60 and RSAD2) are known to be induced by type 1 IFN. ${ }^{97}$ Limitations of both studies include the fact that LN was defined based on a history of meeting the American College of Rheumatology (ACR) renal criterion and not the presence of active lupus nephritis or histological features. Further, neither study fully accounted for medication use at the time of DNA collection.

\section{Autoantibody production}

In a study of 326 women of European descent with SLE, methylation differences were compared between patients with and without a history of anti-dsDNA antibody positivity. Peripheral blood mononuclear cells were profiled with the HM450 array. Using a discovery and replication study design, $16 \mathrm{CpG}$ sites in 11 genes were found to be differentially methylated. Seven of these genes are either induced by type 1 IFN (IFIT1, IFI44L, MX1, RSAD2, OAS1, EIF2AK2) or regulate type 1 IFN signalling (NLRC5). These CpG sites were also associated with anti-Sm,
anti-RNP and anti-SSA status, with anti-Sm and anti-RNP having a stronger association with hypomethylation than anti-dsDNA or anti-SSA. The PARP9/DTX3L locus was associated with all four autoantibodies studied, and mediates ubiquitination of histone $\mathrm{H} 4$ in response to DNA damage to perform DNA-damage repair. ${ }^{98}$ Hypomethylation of RABGAP1L was also associated with the four autoantibodies, and copy number variants of this gene have been associated with SLE risk. ${ }^{99}$ This gene encodes for a tyrosine kinase that regulates the activity of the mTOR complex 1 signalling pathway. ${ }^{100}$ However, another study of similar size examining methylation differences between patients according to the ACR immunologic criteria did not find statistically significant differentially methylated CpGs. ${ }^{92}$ It is unclear whether an analysis focusing specifically on ds-DNA antibody status or other specific autoantibodies would have revealed different results.

Further studies are needed to fully elucidate the contribution of DNA methylation to disease heterogeneity. This will likely aid in subtyping patients with SLE according to their most prominent methylation marks or patterns with the potential of informing therapeutic approaches and stratification in clinical trials. Limitations of the aforementioned studies include small sample sizes and different methodologic approaches. But perhaps the main limitation is the difficulty of capturing patients with active disease manifestations rather than historical disease manifestations.

\section{Environmental exposures, DNA methylation and SLE}

Many lifestyle factors, including diet, obesity, physical activity, tobacco smoking, alcohol consumption, environmental pollutants and psychological stress, have been shown to modify DNA methylation patterns. ${ }^{101-104}$ For example, environmental chemicals directly act on the function of DNMT and TET enzyme families. In addition, chemicals may affect the availability of SAM. Still, what drives gene-specific DNA methylation patterns remains unclear. A failure to maintain epigenetic homeostasis in the immune response due to factors including environmental influences leads to aberrant gene expression, contributing to immune dysfunction and, in some cases, the development of autoimmunity in genetically predisposed individuals. An exposure or multiple exposures could also contribute to the flare/relapse nature of SLE. Table 1 summarises the relationship between exposures and changes in methylation, as well as their independent associations with SLE. ${ }^{105}$ Although DNA methylation perturbations have been viewed mostly as a mechanism to explain how exposures can lead to disease, there is increasing evidence that DNA methylation marks or 'signatures' can be used as biomarkers of exposure. As most environmental and residential exposures are difficult to accurately measure, this area of research is of great value. For example, studies of adults have shown that methylation levels at specific smoking-associated loci reflect cigarette pack years and time since quitting. ${ }^{106}$ 


\section{Future directions}

Future EWAS and DNA methylation studies in SLE should be designed to examine not only relevant cell type(s) and tissues, such as skin and kidney, but also the specific context (active vs inactive disease). Larger samples sizes and longitudinal studies of DNA methylation changes in SLE may clarify some of the findings discussed in this review. Finally, SLE EWAS in different populations and different geographic regions or environments could also shed light on disease pathogenesis. Single-cell profiling has emerged as a potentially powerful way to ascertain cell subtype composition at higher resolution. Singlecell epigenomic methods have been developed ${ }^{107-109}$ and will likely be implemented in future SLE studies. Integrating these approaches with parallel methods, such as ATAC-seq, which provides a comprehensive map of chromatin accessibility where DNA methylation changes might be important, and RNA-seq that provides comprehensive transcriptomic data, will allow for correlation of epigenetic modifications with causative and downstream effects. These studies are currently costly and analytically challenging to undertake; however, the relevant technologies are developing rapidly and will likely be feasible for application to SLE in the near future. Most EWAS results will probably require experiments with animal or cellular models to confirm causality.

\section{Therapeutic implications}

Gene-editing technologies such as those that use the CRISPR/CAS9 system have now have been applied to the enzymatic activities of both DNMTs and TET enzymes, to actively methylate or demethylate specific CpG sites, paving the way for new therapeutic approaches. As our knowledge advances, further understanding of methylbinding domain proteins as well as the allosteric regulators of DNMTs, coupled with a better understanding of specific methylation aberrations in SLE, could lead to potential targeting and correction of DNA methylation marks. As oxidative stress continues to be implicated as a mediator of DNA methylation perturbations, antioxidants such as $\mathrm{N}$-acetyl cysteine have been suggested as safe interventions. Finally, if a link between exposures, DNA methylation and SLE disease risk is firmly established, preventive measures could be undertaken.

Acknowledgements The authors thank Kimberly Taylor and Joanne Nititham for their review and comments on the manuscript.

Contributors CML contributed to the main manuscript preparation. All authors contributed to the discussions and data interpretation that were used to form the review contained in this paper and provided input to the manuscript and approved its final version.

Funding CML received grant/research support from the Rheumatology Research Foundation Scientist Development Award 128849A. CML, SAC and LAC are also supported by NIH P30AR070155, and CML and LAC by the PHS Centers for Disease Control and Prevention DP005120, Alliance for Lupus Research and the Lupus Research Institute/Lupus Foundation of America.

Competing interests None declared.

Patient consent Not required.
Provenance and peer review Commissioned; internally peer reviewed. Data statement All data presented in this article are already published and are not in possession of the authors.

Open access This is an Open Access article distributed in accordance with the Creative Commons Attribution Non Commercial (CC BY-NC 4.0) license, which permits others to distribute, remix, adapt, build upon this work non-commercially, and license their derivative works on different terms, provided the original work is properly cited and the use is non-commercial. See:

\section{REFERENCES}

1. Chen L, Morris DL, Vyse TJ. Genetic advances in systemic lupus erythematosus. Curr Opin Rheumatol 2017;29:423-33.

2. Kuo C-F, Grainge MJ, Valdes AM, et al. Familial aggregation of systemic lupus erythematosus and coaggregation of autoimmune diseases in affected families. JAMA Intern Med 2015;175:1518.

3. Cooper GS, Parks CG. Occupational and environmental exposures as risk factors for systemic lupus erythematosus. Curr Rheumatol Rep 2004;6:367-74.

4. Feinberg AP, Vogelstein B. Hypomethylation distinguishes genes of some human cancers from their normal counterparts. Nature 1983;301:89-92.

5. Bird A. DNA methylation patterns and epigenetic memory. Genes Dev 2002;16:6-21.

6. Klosin A, Casas E, Hidalgo-Carcedo C, et al. Transgenerational transmission of environmental information in C. elegans. Science 2017;356:320-3.

7. Nanney DL. Epigenetic factors affecting mating type expression in certain ciliates. Cold Spring Harb Symp Quant Biol 1958;23:327-35.

8. Holliday R. A new theory of carcinogenesis. Br J Cancer 1979;40:513-22.

9. Riggs AD. X inactivation, differentiation, and DNA methylation. Cytogenet Genome Res 1975;14:9-25.

10. Sarda S, Hannenhalli S. Next-generation sequencing and epigenomics research: a hammer in search of nails. Genomics Inform 2014;12:2-11.

11. Ballestar E. Epigenetic alterations in autoimmune rheumatic diseases. Nat Rev Rheumatol 2011;7:263-71.

12. Jeltsch A, Jurkowska RZ. New concepts in DNA methylation. Trends Biochem Sci 2014;39:310-8.

13. Jones PA. Functions of DNA methylation: islands, start sites, gene bodies and beyond. Nat Rev Genet 2012;13:484-92.

14. Stirzaker C, Taberlay PC, Statham AL, et al. Mining cancer methylomes: prospects and challenges. Trends in Genetics 2014;30:75-84.

15. Irizarry RA, Ladd-Acosta $\mathrm{C}$, Wen $\mathrm{B}$, et al. The human colon cancer methylome shows similar hypo- and hypermethylation at conserved tissue-specific CpG island shores. Nat Genet 2009;41:178-86.

16. Schulz WA, Steinhoff C, Florl AR. Methylation of endogenous human retroelements in health and disease. Curr Top Microbiol Immunol 2006;310:211-50.

17. Domcke S, Bardet AF, Adrian Ginno P, et al. Competition between DNA methylation and transcription factors determines binding of NRF1. Nature 2015;528:575-9.

18. Clouaire T, Stancheva I. Methyl-CpG binding proteins: specialized transcriptional repressors or structural components of chromatin? Cellular and Molecular Life Sciences 2008;65:1509-22.

19. Balada E, Ordi-Ros J, Serrano-Acedo S, et al. Transcript overexpression of the MBD2 and MBD4 genes in $\mathrm{CD} 4^{+} \mathrm{T}$ cells from systemic lupus erythematosus patients. J Leukoc Biol 2007;81:1609-16.

20. Liu CC, Ou TT, Wu CC, et al. Global DNA methylation, DNMT1, and MBD2 in patients with systemic lupus erythematosus. Lupus 2011;20:131-6.

21. Okano M, Xie S, Li E. Cloning and characterization of a family of novel mammalian DNA (cytosine-5) methyltransferases. Nat Genet 1998;19:219-20.

22. Gowher $\mathrm{H}$, Jeltsch $\mathrm{A}$. Enzymatic properties of recombinant Dnmt3a DNA methyltransferase from mouse: the enzyme modifies DNA in a non-processive manner and also methylates non-CpA sites. J Mol Biol 2001;309:1201-8.

23. Jeltsch A, Jurkowska RZ. Allosteric control of mammalian DNA methyltransferases - a new regulatory paradigm. Nucleic Acids Res 2016;44:8556-75.

24. Jurkowska RZ, Jurkowski TP, Jeltsch A. Structure and function of mammalian DNA methyltransferases. Chembiochem 2011;12:206-22. 
25. Rondelet G, Dal Maso T, Willems L, et al. Structural basis for recognition of histone H3K36me3 nucleosome by human de novo DNA methyltransferases $3 \mathrm{~A}$ and 3B. J Struct Biol 2016;194:357-67.

26. Di Ruscio A, Ebralidze AK, Benoukraf T, et al. DNMT1interacting RNAs block gene-specific DNA methylation. Nature 2013;503:371-6.

27. Liu X, Gao Q, Li P, et al. UHRF1 targets DNMT1 for DNA methylation through cooperative binding of hemi-methylated DNA and methylated H3K9. Nat Commun 2013;4:1563.

28. Plasschaert RN, Bartolomei MS. Genomic imprinting in development, growth, behavior and stem cells. Development 2014;141:1805-13.

29. Dao T, Hong X, Wang $X$, et al. Aberrant $5^{\prime}-\mathrm{CpG}$ methylation of cord blood TNF $\alpha$ associated with maternal exposure to polybrominated diphenyl ethers. PLoS One 2015;10:e0138815.

30. Flanagan JM, Brook MN, Orr N, et al. Temporal stability and determinants of white blood cell DNA methylation in the breakthrough generations study. Cancer Epidemiol Biomarkers Prev 2015;24:221-9.

31. Feinberg AP, Irizarry RA, Fradin D, et al. Personalized epigenomic signatures that are stable over time and covary with body mass index. Sci Transl Med 2010;2:ra67.

32. Chen S, Mukherjee N, Janjanam VD, et al. Consistency and variability of DNA methylation in women during puberty, young adulthood, and pregncy. Genet Epigenet 2017;9:1179237X17721540.

33. Tan Q, Heijmans BT, Hjelmborg JV, et al. Epigenetic drift in the aging genome: a ten-year follow-up in an elderly twin cohort. Int $J$ Epidemiol 2016;45:dyw132-58.

34. Hong KM, Kim HK, Park SY, et al. CD3Z hypermethylation is associated with severe clinical manifestations in systemic lupus erythematosus and reduces CD3囚-chain expression in T cells. Rheumatology 2017;56:467-76.

35. Lee PP, Fitzpatrick DR, Beard C, et al. A critical role for Dnmt1 and DNA methylation in T cell development, function, and survival. Immunity 2001;15:763-74.

36. Bruniquel D, Schwartz RH. Selective, stable demethylation of the interleukin-2 gene enhances transcription by an active process. Nat Immunol 2003;4:235-40.

37. Morikawa H, Sakaguchi S. Genetic and epigenetic basis of Treg cell development and function: from a FoxP3-centered view to an epigenome-defined view of natural Treg cells. Immunol Rev 2014;259:192-205.

38. Wang J, Syrett CM, Kramer MC, et al. Unusual maintenance of $X$ chromosome inactivation predisposes female lymphocytes for increased expression from the inactive X. Proc Natl Acad Sci U S A 2016;113:E2029-E2038.

39. Carrel L, Willard HF. Heterogeneous gene expression from the inactive $\mathrm{X}$ chromosome: an $\mathrm{X}$-linked gene that escapes $\mathrm{X}$ inactivation in some human cell lines but is inactivated in others. Proc Natl Acad Sci U S A 1999;96:7364-9.

40. Cooney CM, Bruner GR, Aberle T, et al. 46,X,del(X)(q13) Turner's syndrome women with systemic lupus erythematosus in a pedigree multiplex for SLE. Genes \& Immunity 2009;10:478-81.

41. Scofield RH, Bruner GR, Namjou B, et al. Klinefelter's syndrome $(47, X X Y)$ in male systemic lupus erythematosus patients: support for the notion of a gene-dose effect from the $X$ chromosome. Arthritis Rheum 2008;58:2511-7.

42. Lu Q, Wu A, Tesmer L, et al. Demethylation of CD40LG on the inactive $X$ in $T$ cells from women with lupus. J Immunol 2007;179:6352-8.

43. Hewagama A, Gorelik G, Patel D, et al. Overexpression of $X$-linked genes in T cells from women with lupus. J Autoimmun 2013;41:60-71.

44. Goodier JL, Kazazian HH. Retrotransposons revisited: the restraint and rehabilitation of parasites. Cell 2008;135:23-35.

45. Levin HL, Moran JV. Dynamic interactions between transposable elements and their hosts. Nat Rev Genet 2011;12:615-27.

46. Mavragani CP, Sagalovskiy I, Guo Q, et al. Expression of long interspersed nuclear element 1 retroelements and induction of type I interferon in patients with systemic autoimmune disease. Arthritis Rheumatol 2016;68:2686-96.

47. Fali T, Le Dantec C, Thabet $\mathrm{Y}$, et al. DNA methylation modulates HRES1/p28 expression in B cells from patients with Lupus. Autoimmunity 2014;47:265-71.

48. Nawrocki MJ, Majewski D, Puszczewicz M, et al. Decreased mRNA expression levels of DNA methyltransferases type 1 and $3 A$ in systemic lupus erythematosus. Rheumatol Int 2017;37:775-83.

49. Gorelik G, Richardson B. Key role of ERK pathway signaling in lupus. Autoimmunity 2010;43:17-22.
50. Li Y, Gorelik G, Strickland FM, et al. T Cell DNA methylation and lupus. Arthritis \& rheumatology 2014;66:1574-82.

51. Park JK, Kim J-Y, Moon JY, et al. Altered lipoproteins in patients with systemic lupus erythematosus are associated with augmented oxidative stress: a potential role in atherosclerosis. Arthritis Res Ther 2016;18:306.

52. Somers EC, Richardson BC. Environmental exposures, epigenetic changes and the risk of lupus. Lupus 2014;23:568-76.

53. He YF, Li BZ, Li Z, et al. Tet-mediated formation of 5-carboxylcytosine and its excision by TDG in mammalian DNA. Science 2011;333:1303-7.

54. Ito $\mathrm{S}$, Shen $\mathrm{L}$, Dai $\mathrm{Q}$, et al. Tet proteins can convert 5-methylcytosine to 5-formylcytosine and 5-carboxylcytosine. Science 2011;333:1300-3.

55. Smiley JA, Kundracik M, Landfried DA, et al. Genes of the thymidine salvage pathway: thymine-7-hydroxylase from a Rhodotorula glutinis cDNA library and iso-orotate decarboxylase from Neurospora crassa. Biochim Biophys Acta 2005;1723:256-64.

56. Maiti A, Drohat AC. Thymine DNA glycosylase can rapidly excise 5-formylcytosine and 5-carboxylcytosine: potential implications for active demethylation of CpG sites. J Biol Chem 2011;286:35334-8.

57. Weber AR, Krawczyk C, Robertson AB, et al. Biochemical reconstitution of TET1-TDG-BER-dependent active DNA demethylation reveals a highly coordinated mechanism. Nat Commun 2016;7:10806.

58. Wu X, Zhang Y. TET-mediated active DNA demethylation: mechanism, function and beyond. Nat Rev Genet 2017;18:517-34.

59. Lister R, Pelizzola M, Dowen RH, et al. Human DNA methylomes at base resolution show widespread epigenomic differences. Nature 2009;462:315-22.

60. Bibikova M, Barnes B, Tsan C, et al. High density DNA methylation array with single CpG site resolution. Genomics 2011;98:288-95.

61. Hebestreit K, Dugas M, Klein H-U. Detection of significantly differentially methylated regions in targeted bisulfite sequencing data. Bioinformatics 2013;29:1647-53.

62. Birney E, Smith GD, Greally JM. Epigenome-wide association studies and the interpretation of disease -omics. PLOS Genet 2016;12:e1006105.

63. Michels KB, Binder AM, Dedeurwaerder S, et al. Recommendations for the design and analysis of epigenome-wide association studies. Nat Methods 2013;10:949-55.

64. Lappalainen T, Greally JM. Associating cellular epigenetic models with human phenotypes. Nat Rev Genet 2017;18:441-51.

65. Rakyan VK, Down TA, Balding DJ, et al. Epigenome-wide association studies for common human diseases. Nat Rev Genet 2011;12:529-41.

66. Heijmans BT, Mill J. Commentary: the seven plagues of epigenetic epidemiology. Int J Epidemiol 2012;41:74-8.

67. Yousefi P, Huen K, Schall RA, Aguilar Schall R, et al. Considerations for normalization of DNA methylation data by Illumina $450 \mathrm{~K}$ BeadChip assay in population studies. Epigenetics 2013;8:1141-52.

68. Paul F, Arkin Y, Giladi A, et al. Transcriptional heterogeneity and lineage commitment in myeloid progenitors. Cell 2015;163:1663-77.

69. Jaitin DA, Kenigsberg E, Keren-Shaul H, et al. Massively parallel single-cell RNA-seq for marker-free decomposition of tissues into cell types. Science 2014;343:776-9.

70. Houseman EA, Accomando WP, Koestler DC, et al. DNA methylation arrays as surrogate measures of cell mixture distribution. BMC Bioinformatics 2012;13:86.

71. McGregor K, Bernatsky S, Colmegna I, et al. An evaluation of methods correcting for cell-type heterogeneity in DNA methylation studies. Genome Biol 2016;17:84.

72. Rahmani E, Zaitlen N, Baran Y, et al. Sparse PCA corrects for cell type heterogeneity in epigenome-wide association studies. Nat Methods 2016;13:443-5.

73. Chen L, Ge B, Casale FP. Genetic drivers of epigenetic and transcriptional variation in human immune Cells. Cell 2016;167:1398-414.

74. Bell JT, Tsai PC, Yang TP, et al. Epigenome-wide scans identify differentially methylated regions for age and age-related phenotypes in a healthy ageing population. PLoS Genet 2012;8:e1002629.

75. Grundberg E, Meduri E, Sandling JK, et al. Global analysis of DNA methylation variation in adipose tissue from twins reveals links to disease-associated variants in distal regulatory elements. Am J Hum Genet 2013;93:876-90.

76. Busche S, Shao X, Caron M, et al. Population whole-genome bisulfite sequencing across two tissues highlights the environment as the principal source of human methylome variation. Genome Biol 2015;16:290.

77. Ballestar E. Epigenetics lessons from twins: prospects for autoimmune disease. Clin Rev Allergy Immunol 2010;39:30-41. 
78. Coit P, Ognenovski M, Gensterblum E, et al. Ethnicity-specific epigenetic variation in naïve CD4+ T cells and the susceptibility to autoimmunity. Epigenetics Chromatin 2015;8:49.

79. Lötsch J, Schneider G, Reker D, et al. Common non-epigenetic drugs as epigenetic modulators. Trends Mol Med 2013;19:742-53.

80. Imgenberg-Kreuz J, Carlsson Almlöf J, Leonard D, et al. DNA methylation mapping identifies gene regulatory effects in patients with systemic lupus erythematosus. Ann Rheum Dis 2018;77:736-43.

81. de Andres MC, Perez-Pampin E, Calaza M, et al. Assessment of global DNA methylation in peripheral blood cell subpopulations of early rheumatoid arthritis before and after methotrexate. Arthritis Res Ther 2015;17:233.

82. Richardson B, Scheinbart L, Strahler J, et al. Evidence for impaired T cell DNA methylation in systemic lupus erythematosus and rheumatoid arthritis. Arthritis Rheum 1990;33:1665-73.

83. Richardson B. Effect of an inhibitor of DNA methylation on T cells. II. 5-Azacytidine induces self-reactivity in antigen-specific T4+ cells. Hum Immunol 1986;17:456-70.

84. Richardson B, Sawalha AH, Ray D, et al. Murine models of lupus induced by hypomethylated T cells (DNA hypomethylation and lupus...). Methods Mol Biol 2012;900:169-80.

85. Lu Q, Kaplan M, Ray D, et al. Demethylation ofITGAL (CD11a) regulatory sequences in systemic lupus erythematosus. Arthritis \& Rheumatism 2002;46:1282-91.

86. Strickland FM, Patel D, Khanna D, et al. Characterisation of an epigenetically altered $\left.\left.\mathrm{CD} 4^{(+}\right) \mathrm{CD} 8^{(+)} \mathrm{Kir}^{(+)}\right) \mathrm{T}$ cell subset in autoimmune rheumatic diseases by multiparameter flow cytometry. Lupus Sci Med 2016;3:e000147.

87. Coit P, Jeffries M, Altorok N, et al. Genome-wide DNA methylation study suggests epigenetic accessibility and transcriptional poising of interferon-regulated genes in naïve CD4+ T cells from lupus patients. J Autoimmun 2013;43:78-84.

88. Absher DM, Li X, Waite LL, et al. Genome-wide DNA methylation analysis of systemic lupus erythematosus reveals persistent hypomethylation of interferon genes and compositional changes to CD4+ T-cell populations. PLoS Genet 2013;9:e1003678.

89. Coit P, Yalavarthi S, Ognenovski M, et al. Epigenome profiling reveals significant DNA demethylation of interferon signature genes in lupus neutrophils. J Autoimmun 2015;58:59-66.

90. Ulff-Møller CJ, Asmar F, Liu Y, et al. Twin DNA methylation profiling reveals flare-dependent interferon signature and $\mathrm{B}$ cell promoter hypermethylation in systemic Lupus erythematosus. Arthritis Rheumatol 2018;70:878-90.

91. Buchta CM, Bishop GA. TRAF5 negatively regulates TLR signaling in B lymphocytes. J Immunol 2014;192:145-50.

92. Imgenberg-Kreuz J, Carlsson Almlöf J, Leonard D, et al. DNA methylation mapping identifies gene regulatory effects in patients with systemic lupus erythematosus. Ann Rheum Dis 2018;77:736-43.

93. Lin S-Y, Hsieh S-C, Lin Y-C, et al. A whole genome methylation analysis of systemic lupus erythematosus: hypomethylation of the IL10 and IL1R2 promoters is associated with disease activity. Genes \& Immunity 2012;13:214-20.

94. Coit P, Dozmorov MG, Merrill JT, et al. Epigenetic reprogramming in naive CD4+ T cells favoring T cell activation and Non-Th1 effector $\mathrm{T}$ cell immune response as an early event in Lupus flares. Arthritis Rheumatol 2016;68:2200-9.

95. Tsou P-S, Coit P, Kilian NC, et al. EZH2 modulates the DNA methylome and controls $\mathrm{T}$ cell adhesion through junctional adhesion molecule A in lupus patients. Arthritis Rheumatol 2018;70:98-108.

96. Coit $P$, Renauer $P$, Jeffries MA, et al. Renal involvement in lupus is characterized by unique DNA methylation changes in naïve CD4+ T cells. J Autoimmun 2015;61:29-35.

97. Mok A, Solomon O, Nayak RR, et al. Genome-wide profiling identifies associations between lupus nephritis and differential methylation of genes regulating tissue hypoxia and type 1 interferon responses. Lupus Sci Med 2016;3:e000183.

98. Yang C-S, Jividen K, Spencer A, et al. Ubiquitin modification by the E3 ligase/ADP-Ribosyltransferase Dtx3L/Parp9. Mol Cell 2017;66:503-16.

99. Kim JH, Jung $\mathrm{SH}$, Bae JS, et al. Deletion variants of RABGAP1L, $10 \mathrm{q} 21.3$, and $C 4$ are associated with the risk of systemic lupus erythematosus in Korean women. Arthritis Rheum 2013;65:1055-63.

100. Roberti MC, La Starza R, Surace $C$, et al. RABGAP1L gene rearrangement resulting from a $\operatorname{der}(\mathrm{Y}) \mathrm{t}(\mathrm{Y} ; 1)(\mathrm{q} 12 ; \mathrm{q} 25)$ in acute myeloid leukemia arising in a child with Klinefelter syndrome. Virchows Archiv 2009;454:311-6.

101. Perera F, Herbstman J. Prenatal environmental exposures, epigenetics, and disease. Reprod Toxicol 2011;31:363. --73.
102. Klengel T, Pape J, Binder EB, et al. The role of DNA methylation in stress-related psychiatric disorders. Neuropharmacology 2014;80:115-32.

103. Langevin SM, Houseman EA, Christensen BC, et al. The influence of aging, environmental exposures and local sequence features on the variation of DNA methylation in blood. Epigenetics 2011;6:908-19.

104. Stover PJ, James WPT, Krook A, et al. Emerging concepts on the role of epigenetics in the relationships between nutrition and health. J Intern Med 2018:284:37-49.

105. Martin EM, Fry RC. Environmental influences on the epigenome: exposure-associated DNA methylation in human populations. Annu Rev Public Health 2018:39:309-33.

106. Elliott HR, Tillin T, McArdle WL, et al. Differences in smoking associated DNA methylation patterns in South Asians and Europeans. Clin Epigenetics 2014;6:4.

107. Smallwood SA, Lee HJ, Angermueller C, et al. Single-cell genomewide bisulfite sequencing for assessing epigenetic heterogeneity. Nat Methods 2014;11:817-20.

108. Angermueller C, Clark SJ, Lee HJ, et al. Parallel single-cell sequencing links transcriptional and epigenetic heterogeneity. Nat Methods 2016;13:229-32.

109. Farlik M, Sheffield NC, Nuzzo A, et al. Single-cell DNA methylome sequencing and bioinformatic inference of epigenomic cell-state dynamics. Cell Rep 2015;10:1386-97.

110. Alegría-Torres JA, Carrizales-Yánez L, Díaz-Barriga F, et al. DNA methylation changes in Mexican children exposed to arsenic from two historic mining areas in San Luis potosí. Environ Mol Mutagen 2016;57:717-23.

111. Das N, Paul S, Chatterjee D, et al. Arsenic exposure through drinking water increases the risk of liver and cardiovascular diseases in the population of West Bengal, India. BMC Public Health 2012;12:639.

112. Gonzalez-Cortes T, Recio-Vega R, Lantz RC, et al. DNA methylation of extracellular matrix remodeling genes in children exposed to arsenic. Toxicol Appl Pharmacol 2017;329:140-7.

113. Kaushal A, Zhang H, Karmaus WJJ, et al. Genome-wide DNA methylation at birth in relation to in utero arsenic exposure and the associated health in later life. Environ Health 2017;16:50.

114. Rea M, Eckstein M, Eleazer R, et al. Genome-wide DNA methylation reprogramming in response to inorganic arsenic links inhibition of CTCF binding, DNMT expression and cellular transformation. Sci Rep 2017;7:41474.

115. Alves AGF, de Azevedo Giacomin MF, Braga ALF, et al. Influence of air pollution on airway inflammation and disease activity in childhood-systemic lupus erythematosus. Clin Rheumatol 2018;37:683-690.

116. Bernatsky S, Fournier M, Pineau CA, et al. Associations between ambient fine particulate levels and disease activity in patients with systemic lupus erythematosus (SLE). Environ Health Perspect 2011;119:45-9.

117. Bernatsky S, Smargiassi A, Johnson M, et al. Fine particulate air pollution, nitrogen dioxide, and systemic autoimmune rheumatic disease in Calgary, Alberta. Environ Res 2015;140:474-8.

118. De Prins S, Koppen G, Jacobs G, et al. Influence of ambient air pollution on global DNA methylation in healthy adults: a seasonal follow-up. Environ Int 2013;59:418-24.

119. Guo L, Byun HM, Zhong J, et al. Effects of short-term exposure to inhalable particulate matter on DNA methylation of tandem repeats. Environ Mol Mutagen 2014;55:322-35.

120. Madrigano J, Baccarelli A, Mittleman MA, et al. Prolonged exposure to particulate pollution, genes associated with glutathione pathways, and DNA methylation in a cohort of older men. Environ Health Perspect 2011;119:977-82.

121. Yurino $\mathrm{H}$, Ishikawa S, Sato T, et al. Endocrine disruptors (environmental estrogens) enhance autoantibody production by B1 cells. Toxicol Sci 2004;81:139-47.

122. Bromer JG, Zhou Y, Taylor MB, et al. Bisphenol-A exposure in utero leads to epigenetic alterations in the developmental programming of uterine estrogen response. Faseb J 2010;24:2273-80.

123. Calafat AM, Kuklenyik Z, Reidy JA, Ja R, et al. Urinary concentrations of bisphenol $A$ and 4-nonylphenol in a human reference population. Environ Health Perspect 2005;113:391-5.

124. Doherty LF, Bromer JG, Zhou Y, et al. In utero exposure to diethylstilbestrol (DES) or bisphenol-A (BPA) increases EZH2 expression in the mammary gland: an epigenetic mechanism linking endocrine disruptors to breast cancer. Horm Cancer 2010;1:146-55.

125. Du L, Sun W, Li XM, et al. DNA methylation and copy number variation analyses of human embryonic stem cell-derived neuroprogenitors after low-dose decabromodiphenyl ether and/or bisphenol A exposure. Hum Exp Toxicol 2018;37:475-85. 
126. Faulk C, Kim JH, Jones TR, et al. Bisphenol A-associated alterations in genome-wide DNA methylation and gene expression patterns reveal sequence-dependent and non-monotonic effects in human fetal liver. Environ Epigenet 2015;1:dvv006.

127. Hanna CW, Bloom MS, Robinson WP, et al. DNA methylation changes in whole blood is associated with exposure to the environmental contaminants, mercury, lead, cadmium and bisphenol A, in women undergoing ovarian stimulation for IVF. Hum Reprod 2012;27:1401-10.

128. Li J, Li W, Yin H, et al. [Effect of cadmium on TET enzymes and DNA methylation changes in human embryonic kidney cell]. Zhonghua Yu Fang Yi Xue Za Zhi 2015;49:822-7.

129. Sanders AP, Smeester L, Rojas D, et al. Cadmium exposure and the epigenome: Exposure-associated patterns of DNA methylation in leukocytes from mother-baby pairs. Epigenetics 2014;9:212-21.

130. Virani S, Rentschler KM, Nishijo M, et al. DNA methylation is differentially associated with environmental cadmium exposure based on sex and smoking status. Chemosphere 2016;145:284-90.

131. Zhou ZH, Lei YX, Wang CX. Analysis of aberrant methylation in DNA repair genes during malignant transformation of human bronchial epithelial cells induced by cadmium. Toxicol Sci 2012;125:412-7.

132. Schoeters G, Den Hond E, Zuurbier M, et al. Cadmium and children: exposure and health effects. Acta Paediatr Supp/ 2006;95:50-4.

133. Bakulski KM, Lee H, Feinberg Jl, et al. Prenatal mercury concentration is associated with changes in DNA methylation at TCEANC2 in newborns. Int J Epidemiol 2015;44:1249-62.

134. Cardenas A, Koestler DC, Houseman EA, et al. Differential DNA methylation in umbilical cord blood of infants exposed to mercury and arsenic in utero. Epigenetics 2015;10:508-15.

135. Cardenas A, Rifas-Shiman SL, Agha G, et al. Persistent DNA methylation changes associated with prenatal mercury exposure and cognitive performance during childhood. Sci Rep 2017;7:288.

136. Goodrich JM, Basu N, Franzblau A, et al. Mercury biomarkers and DNA methylation among Michigan dental professionals. Environ Mol Mutagen 2013;54:195-203.

137. Maccani JZ, Koestler DC, Lester B, et al. Placental DNA Methylation Related to Both Infant Toenail Mercury and Adverse Neurobehavioral Outcomes. Environ Health Perspect 2015:123:723-9.

138. Olsvik PA, Williams TD, Tung HS, et al. Impacts of TCDD and $\mathrm{MeHg}$ on DNA methylation in zebrafish (Danio rerio) across two generations. Comp Biochem Physiol C Toxicol Pharmacol 2014;165:17-27.

139. Huen K, Yousefi P, Bradman A, et al. Effects of age, sex, and persistent organic pollutants on DNA methylation in children. Environ Mol Mutagen 2014;55:209-22.

140. Tsai PC, Ko YC, Huang W, et al. Increased liver and lupus mortalities in 24-year follow-up of the Taiwanese people highly exposed to polychlorinated biphenyls and dibenzofurans. Sci Total Environ 2007;374:216-22.

141. Tan W, Sunahori K, Zhao J, et al. Association of PPP2CA polymorphisms with systemic lupus erythematosus susceptibility in multiple ethnic groups. Arthritis Rheum 2011;63:2755-63.

142. Kamen DL. Environmental influences on systemic lupus erythematosus expression. Rheum Dis Clin North Am 2014;40:401-12.

143. Cooper GS, Wither J, Bernatsky S, et al. Occupational and environmental exposures and risk of systemic lupus erythematosus: silica, sunlight, solvents. Rheumatology 2010;49:2172-80.

144. Gold LS, Ward MH, Dosemeci M, et al. Systemic autoimmune disease mortality and occupational exposures. Arthritis Rheum 2007;56:3189-201.

145. Parks CG, De Roos AJ. Pesticides, chemical and industrial exposures in relation to systemic lupus erythematosus. Lupus 2014;23:527-36.

146. Manikkam M, Haque MM, Guerrero-Bosagna C, et al. Pesticide methoxychlor promotes the epigenetic transgenerational inheritance of adult-onset disease through the female germline. PLoS One 2014;9:e102091-e.

147. Rusiecki JA, Beane Freeman LE, Bonner MR, et al. High pesticide exposure events and DNA methylation among pesticide applicators in the agricultural health study. Environ Mol Mutagen 2017;58:19-29.

148. Schug TT, Janesick A, Blumberg B, et al. Endocrine disrupting chemicals and disease susceptibility. J Steroid Biochem Mol Biol 2011;127:204-15.

149. Sobel ES, Gianini J, Butfiloski EJ, et al. Acceleration of autoimmunity by organochlorine pesticides in (NZB x NZW)F1 mice. Environ Health Perspect 2005;113:323-8.
150. Wang A, Padula A, Sirota M, et al. Environmental influences on reproductive health: the importance of chemical exposures. Fertil Steril 2016;106:905-29.

151. Wang F, Roberts SM, Butfiloski EJ, et al. Acceleration of autoimmunity by organochlorine pesticides: a comparison of splenic B-cell effects of chlordecone and estradiol in (NZBXNZW)F1 mice. Toxicol Sci 2007;99:141-52.

152. Zhang $X$, Wallace $A D$, Du $P$, et al. DNA methylation alterations in response to pesticide exposure in vitro. Environ Mol Mutagen 2012;53:542-9.

153. Herbstman JB, Tang D, Zhu D, et al. Prenatal exposure to polycyclic aromatic hydrocarbons, benzo[a]pyrene-DNA adducts, and genomic DNA methylation in cord blood. Environ Health Perspect 2012;120:733-8.

154. Lee J, Kalia V, Perera F, et al. Prenatal airborne polycyclic aromatic hydrocarbon exposure, LINE1 methylation and child development in a Chinese cohort. Environ Int 2017;99:315-20.

155. Dahlgren J, Takhar H, Anderson-Mahoney P, et al. Cluster of systemic lupus erythematosus (SLE) associated with an oil field waste site: a cross sectional study. Environ Health 2007;6:8.

156. Kang SC, Lee BM. DNA methylation of estrogen receptor alpha gene by phthalates. J Toxicol Environ Health A 2005;68(2324):1995-2003.

157. Wu H, Estill MS, Shershebnev A, et al. Preconception urinary phthalate concentrations and sperm DNA methylation profiles among men undergoing IVF treatment: a cross-sectional study. Hum Reprod 2017;32:2159-69.

158. Watkins DJ, Milewski S, Domino SE, et al. Maternal phthalate exposure during early pregnancy and at delivery in relation to gestational age and size at birth: a preliminary analysis. Reprod Toxicol 2016;65:59-66.

159. Huen K, Calafat AM, Bradman A, et al. Maternal phthalate exposure during pregnancy is associated with DNA methylation of LINE-1 and Alu repetitive elements in Mexican-American children. Environ Res 2016;148:55-62.

160. Abdool Karim SS, Naidoo K, Grobler A, et al. Integration of antiretroviral therapy with tuberculosis treatment. N Engl J Med 2011;365:1492-501.

161. Lim SY, Ghosh SK. Autoreactive responses to environmental factors: 3 . Mouse strain-specific differences in induction and regulation of anti-DNA antibody responses due to phthalateisomers. J Autoimmun 2005;25:33-45.

162. Lim SY, Ghosh SK. Autoreactive responses to an environmental factor. 2. Phthalate-induced anti-DNA specificity is downregulated by autoreactive cytotoxic T cells. Immunology 2004;112:94-104.

163. Barbhaiya M, Tedeschi SK, Lu B, et al. Cigarette smoking and the risk of systemic lupus erythematosus, overall and by anti-double stranded DNA antibody subtype, in the Nurses' Health Study cohorts. Ann Rheum Dis 2018;77:196-202.

164. Bernatsky S, Ramsey-Goldman R, Petri M, et al. Smoking Is the most significant modifiable lung cancer risk factor in systemic lupus erythematosus. J Rheumatol 2018;45:393-6.

165. Ma Y, Li MD. Establishment of a strong link between smoking and cancer pathogenesis through dna methylation analysis. Sci Rep 2017;7:1811.

166. Marabita F, Almgren M, Sjöholm LK, et al. Smoking induces DNA methylation changes in Multiple Sclerosis patients with exposureresponse relationship. Sci Rep 2017;7:14589.

167. Tehranifar $\mathrm{P}, \mathrm{Wu} \mathrm{HC}, \mathrm{McD}$ nald JA, et al. Maternal cigarette smoking during pregnancy and offspring DNA methylation in midlife. Epigenetics 2018;13:129-34.

168. Freemer MM, King TE, Criswell LA. Association of smoking with dsDNA autoantibody production in systemic lupus erythematosus. Ann Rheum Dis 2006;65:581-4.

169. Reese SE, Zhao S, Wu MC. DNA methylation score as a biomarker in newborns for sustained maternal smoking during pregnancy. Environ Health Perspect 2017;125:760-6.

170. Richmond RC, Simpkin AJ, Woodward G, et al. Prenatal exposure to maternal smoking and offspring DNA methylation across the lifecourse: findings from the Avon Longitudinal Study of Parents and Children (ALSPAC). Hum Mol Genet 2015;24:2201-17.

171. Wu H, Huang $X$, Qiu $H$, et al. High salt promotes autoimmunity by TET2-induced DNA demethylation and driving the differentiation of Tfh cells. Sci Rep 2016;6:28065.

172. Clukay CJ, Hughes DA, Rodney NC, et al. DNA methylation of methylation complex genes in relation to stress and genomewide methylation in mother-newborn dyads. Am J Phys Anthropol 2018;165:173-82.

173. Milaniak I, Cecil CAM, Barker ED, et al. Variation in DNA methylation of the oxytocin receptor gene predicts children's resilience to prenatal stress. Dev Psychopathol 2017;29:1663-74. 
174. Serpeloni F, Radtke K, de Assis SG, et al. Grandmaternal stress during pregnancy and DNA methylation of the third generation: an epigenome-wide association study. Transl Psychiatry 2017;7:e1202.

175. Smith JA, Zhao W, Wang X, et al. Neighborhood characteristics influence DNA methylation of genes involved in stress response and inflammation: the multi-ethnic study of atherosclerosis. Epigenetics 2017;12:662-73.
176. Sosnowski DW, Booth C, York TP, et al. Maternal prenatal stress and infant DNA methylation: A systematic review. Dev Psychobiol 2018;60:127-39.

177. Subramanyam MA, Diez-Roux AV, Pilsner JR, et al. Social factors and leukocyte DNA methylation of repetitive sequences: the multiethnic study of atherosclerosis. PLoS One 2013;8:e54018. 